\title{
Adaptação procedimental em tempos de pandemia reflexões sobre os impactos da crise em nossa cultura jurídica processual ${ }^{1}$
}

\author{
Alexandre de Castro Catharina ${ }^{2}$
}

\section{Resumo}

$\mathrm{O}$ artigo tem como escopo analisar o tratamento normativo dado à adaptação do procedimento pelo Código de Processo Civil e como esta técnica processual vem sendo utilizada, no período de pandemia, para dar maior efetividade à tutela jurisdicional nos processos que demandam tratamento célere e diferenciado em razão natureza da causa. A partir da análise empírica de alguns casos, pretende-se investigar em quais casos a adaptação procedimental foi utilizada e se as normas fundamentais do direito processual civil foram resguardadas, em especial o contraditório-influência, na aplicação do instituto. A aplicação cooperativa da adaptação procedimental no período da pandemia pode contribuir para melhor assimilação desta técnica processual em nossa cultura jurídica e, como consequência, para maior efetividade do processo. O desenvolvimento do trabalho é apresentado em três partes. Na primeira parte será abordada algumas premissas teóricas acerca do tema objeto do estudo. Na segunda parte serão analisados empiricamente os casos que compõem a amostragem. Na terceira e última parte será analisado o impacto da adaptação procedimental, no período da pandemia, em nossa cultura jurídica processual. Concluiu-se, portanto, que as adaptações realizadas no período da pandemia evidenciaram o instrumentalismo processual, de matiz publicista, que estabelece uma tensão com modelo cooperativo e democrático de processo proposto pelo Código de Processo Civil de 2015. A metodologia de pesquisa empregada no trabalho é qualitativa documental e a abordagem será hermenêutica.

Palavras-chave: Crise pandêmica; Adaptação do procedimento; Processo Civil.

\footnotetext{
${ }^{1} \mathrm{O}$ presente artigo foi elaborado a partir do resumo expandido apresentado no GT 10 - Justiça e novas configurações do direito em cenários de Pandemia, na VI Jornada Internacional sobre Ética, Justiça e Gestão Institucional da Universidade Federal Fluminense-UFF, realizado em 24, 25 e 26 de novembro de 2020.

${ }^{2}$ Professor Permanente do Programa de Pós-Graduação Stricto Sensu da UNESA. Líder do Observatório de Cultura Jurídica e Democratização do Processo - UNESA; Membro do IAB - Instituto dos Advogados Brasileiros - IAB; Membro do Instituto Brasileiro de Direito Processual - IBDP; Membro do Instituto Carioca de Processo Civil - ICPC; Advogado.
} 


\title{
Procedural adaptation in times of pandemics reflections on the impacts of the crisis on our procedural legal culture
}

\begin{abstract}
The purpose of the article is to analyze the normative treatment given to the adaptation of the procedure by the Civil Procedure Code and how this procedural technique has been used, in the pandemic period, to give greater effectiveness to judicial protection in cases that demand swift and differentiated treatment due to nature of the cause. From the empirical analysis of some cases, it is intended to investigate in which cases the procedural adaptation was used and whether the fundamental rules of civil procedural law were safeguarded, especially the contradictory-influence, in the application of the institute. The cooperative application of procedural adaptation during the pandemic period can contribute to a better assimilation of this procedural technique in our legal culture and, as a consequence, to a greater effectiveness of the process. The development of the work is presented in three parts. In the first part, some theoretical premises about the subject matter of the study will be addressed. In the second part, the cases that compose the sample will be analyzed empirically. In the third and last part, the impact of procedural adaptation, during the pandemic period, on our procedural legal culture will be analyzed. It was concluded, therefore, that the adaptations made during the pandemic period showed the procedural instrumentalism, of a publicist hue, which establishes a tension with the cooperative and democratic model of process proposed by the Civil Procedure Code of 2015. The research methodology employed in the work is qualitative documentary and the approach will be hermeneutic.
\end{abstract}

Keywords: Pandemic crisis; Adaptation of the procedure; Civil Procedure.

\section{INTRODUÇÃO}

A crise decorrente da Covid-19 impactou, de forma contundente, diversos países da comunidade internacional. Os efeitos da pandemia desestabilizaram economias e tornaram inequívocas as desigualdades sociais, raciais e de gênero em diversos contextos sociais. No Brasil, a crise repercutiu de forma drástica na vida dos trabalhadores, formais e informais, e tornou manifesta a precariedade da saúde pública e a incapacidade do Estado em superar crises, situação esta agravada pela postura negacionista do Governo Federal.

No campo do Direito, diversas relações jurídicas, previamente estabelecidas, foram afetadas exigindo respostas céleres e adequadas para o reequilíbrio das relações sociais. Neste contexto, contratos de locação comercial foram revistos, mensalidades escolares foram renegociadas, entre outras situações jurídicas. Configurou-se, por essa razão, uma ordem jurídica extraordinária por meio da Lei $\mathrm{n}^{\circ} 14.010$ de 10 de junho de 2020, que tratou, entre 
outros temas, das relações de consumo, das revisões de contrato e do regime da prisão civil por débitos de pensão alimentícia.

Por outro lado, diversos precedentes judiciais foram editados com o objetivo de regular determinadas situações jurídicas no período da crise pandêmica. No Tribunal de Justiça do Estado do Rio de Janeiro, importante precedente judicial foi editado no sentido de impedir a interrupção dos serviços essenciais, por falta de pagamento, no período da crise. Este estado de coisas exigiram uma nova dinâmica no julgamento das diversas ações judiciais distribuídas no âmbito dos tribunais (pedido de suspensão da execução $n^{\circ}$ 0022076-18.2020.8.19.0000).

Com efeito, diante desta situação restou inquestionável as limitações do procedimento comum (art. 318) do Código de Processo Civil para dar conta, em tempo razoável, dos conflitos jurídicos que emergiram no período de crise. Nesta toada, técnicas processuais como negócios processuais atípicos (art. 190) e adaptação procedimental (art. 139, VI) se mostraram eficazes, em alguns contextos, para dar maior celeridade ao tratamento judicial dos conflitos decorrentes da pandemia.

Embora haja certo ceticismo da literatura processual acerca da plena aplicabilidade dos negócios processuais atípicos e da adaptação procedimental em nossa processualística, certo é que estas técnicas processuais vêm sendo aplicadas no período pandêmico com certa regularidade em algumas serventias. Pretende-se, neste contexto, delimitar o estudo na análise das adaptações procedimentais realizadas nos Fóruns Regionais de Madureira e do Méier, período da pandemia, buscando compreender quais atos processuais foram adaptados, em quais tipos de conflitos, e, sobretudo, se as adaptações observaram as normas fundamentais do direito processual civil. Estas decisões judiciais representam dados empíricos importante para se refletir o modus com que a adaptação procedimental é aplicada em nossa processualística e se há violação das normas fundamentais do processo.

A metodologia de pesquisa aplicada ao estudo é qualitativa documental e a abordagem dos dados é indutiva. A partir dos casos estudados é possível se inferir de que modo a adaptação procedimental tem sido assimilado pela cultura jurídica processual brasileira.

\section{ADAPTAÇÃO PROCEDIMENTAL NO PROCESSUAL CIVIL BRASILEIRO}

A adaptação ou flexibilização do procedimento não é uma inovação em nossa processualística $^{3}$. A necessidade de se adaptar o procedimento para dar maior eficácia concretude ao direito material constitui preocupação fundamental da processualística brasileira

\footnotetext{
${ }^{3}$ Trícia Cabral (2010) faz uma ampla análise da produção teórica acerca da adaptação procedimental no período anterior à vigência do Código de Processo Civil de 2015.
} 
(BEDAQUE, 1995), sobretudo na fase denominada por certo segmento da literatura especializada como instrumentalista do processo $^{4}$.

Neste contexto, os poderes do juiz e as formas de flexibilização do procedimento foram objetos das reflexões de processualistas da envergadura de Barbosa Moreira (2007) e Leonardo Greco (2007), o que revela a importância da temática para a processo civil brasileiro.

Embora a reflexão sobre a adaptabilidade do procedimento não seja recente, o Código de Processo Civil de 2015 foi o primeiro ordenamento processual a regulamentar esta técnica no contexto brasileiro. Conforme disposto no art. 139, VI, do CPC, o juiz dirigirá o processo incumbindo-lhe dilatar os prazos processuais e alterar a ordem de produção dos meios de prova, adequando-os às necessidades do conflito de modo a conferir maior efetividade à tutela do direito.

Importante registrar que regramento da adaptação procedimental sofreu significativas alterações durante a tramitação do Projeto de Lei no Congresso. O Projeto de Lei $n^{\circ}$ 166/2010, do Senado, que continha a proposta normativa da Comissão de Juristas presidida pelo Ministro Luiz Fux, dispunha em seu art. 107, V, que o juiz poderia adequar as fases e os atos processuais às especificidades da causa. Com efeito, o Projeto de Lei no 8.046/2010, da Câmara dos Deputados, reduziu consideravelmente o alcance da regra estabelecendo, em seu art. 118, V, que o juiz poderá dilatar os prazos processuais e alterar a ordem de produção dos meios de prova, adequando-os às necessidades do conflito de modo a conferir maior efetividade à tutela do bem jurídico. A redação final do art. 139, VI, do CPC reproduziu integralmente o teor do art. 118, V, do Projeto de Lei n $^{\circ}$ 8.046/2010, reduzindo, sensivelmente, o escopo da adaptação procedimental

Esta redução retrata a tensão existente no campo do direito processual civil entre as perspectivas publicista e privatistas dos modelos processuais em nossa cultura jurídica processual. Prepondera em nossa processualística a visão publicista do processo em que juiz realiza os fins do Estado por meio da jurisdição. Esta perspectiva instrumentalista ${ }^{5}$ do processo, como bem apontou Antônio Carvalho Filho (2019), estabelece premissas epistemológicas que confunde processo com jurisdição, o que contribui para ampliar os poderes do juiz na condução do procedimento. Nesta mesma linha de análise, Igor Raatz e William Galle Dietrich (2018) destacam que um dos principais problemas da leitura publicistas do processo, ou mesmo sociais, é pensar o processo como instrumento da jurisdição, transformando o processo num instrumento incapaz de servir de controle ao poder jurisdicional.

Mesmo as perspectivas teóricas que incorporaram o constitucionalismo contemporâneo, como o modelo de processo justo ou neprocessualismo, atribuem papel preponderante ao juiz, não se afastando da matriz publicista. Analisar a adaptação procedimental na perspectiva

\footnotetext{
4 A perspectiva epistemológica que estrutura a história do processo civil em fases (procedimentalismo, processualismo científico e instrumentalismo) é questionada, de forma interessante por RAATZ, ACHIETA e DIETRICH (2020).

${ }^{5}$ Candido Rangel Dinamarco é um dos principais representantes desta perspectiva instrumentalista do processo. As principais premissas teóricas do autor estão apresentadas no livro Instrumentalidade do Processo.
} 
instrumentalista do processo ou mesmo na perspectiva do processo justo não nos permite estabelecer parâmetros claros para delimitação da atuação do juiz na flexibilização do procedimento (negócios processuais e adaptação do procedimento).

Por outro lado, os modelos democrático, cooperativo e garantista de processo podem viabilizar aplicação adequada da adaptação do procedimento, ajustando-o, efetivamente às necessidades da causa, assegurando maior efetividade do processo através do exercício pleno do contraditório-influência e da condução democratizante do processo decisório. Nestes modelos, em que o processo não se confunde com a jurisdição, a atividade jurisdicional se transforma numa comunidade de trabalho ${ }^{6}$ em que o juiz atua de forma cooperativa, com as partes e terceiros, e o processo passa a ter como principal escopo limitar o exercício do poder jurisdicional.

A despeito deste importante debate, que permanece intenso no campo do direito processual civil e é necessário para o aprofundamento do debate acerca da flexibilização do procedimento em suas diversas variações, pretendemos analisar, neste trabalho, as adaptações procedimentais ocorridas no período da pandemia da Covid-19 e identificar como esta técnica processual foi aplicada na prática forense. Esta abordagem indutiva nos permitirá.

\section{ANÁLISE EMPÍRICA DA ADAPTAÇÃO DO PROCEDIMENTO}

\subsection{Amostragem}

A pesquisa empírica teve como escopo analisar, qualitativamente, 03 casos em que a adaptação do procedimento foi realizada exatamente em razão do período de pandemia ${ }^{7}$. $\mathrm{O}$ primeiro caso ocorreu em um processo que tramita pelo procedimento comum no Fórum Regional de Madureira. Os outros dois casos ocorreram no Fórum Regional do Méier.

Importante ressaltar que foram identificados alguns casos de aplicação da técnica de adaptação do procedimento nas buscas realizadas no sítio do Tribunal de Justiça do Estado do Rio de Janeiro. Entretanto, os casos se limitaram a dilação de prazo em alguns específicos, não promovendo mudanças substanciais na dinâmica do procedimento ${ }^{8}$. Por essa razão, a pesquisa

\footnotetext{
${ }^{6}$ Para maiores detalhes ver MARINONI; ARENHART; MITIDIERO, 2015, p.71.

${ }^{7}$ Os casos foram identificados em nossa prática profissional como advogado. O nosso escritório patrocina as causas que serão analisadas no trabalho. Entretanto, a análise se limitará a adaptação procedimental realizada e o modo que ela foi encaminhada, sem relacionar a aplicação da técnica processual com o desfecho da causa ou com os interesses em conflito. A análise qualitativa da adaptação procedimental pode contribuir para melhor compreensão do instituto em nossa prática forense.

8 A pesquisa realizada, em 19/12/2020, no sítio do Tribunal de Justiça no Estado do Rio de Janeiro, mais especificamente na jurisprudência do referido tribunal, identificou somente 03 casos. A busca foi realizada de duas formas. A primeira utilizou o termo "adaptação procedimental" e "art. 139, VI, do CPC". Não obtivemos nenhum resultado. A segunda utilizou o termo "art. 139, VI, do CPC", onde foram identificados 03 casos de ampliação do prazo utilizando como fundamento o art. 139, VI, do Código de Processo Civil (Processos n $\mathrm{n}^{\circ} 0103881$ 24.2019.8.19.0001, $\mathrm{n}^{\circ}$ 0020757-74.2014.8.19.0210, $\mathrm{n}^{\circ}$ 0070828-55.2019.8.19.0000). Não há dúvidas acerca da
} 
empírica, qualitativa, assentada em estudo de casos nos permitirá importante aproximação com a dinâmica do instituto analisado em nossa prática forense.

Os casos analisados não tramitaram em segredo de justiça, mas optamos por mencionar as iniciais dos nomes das partes. No entanto, os detalhes do processo podem ser pesquisados pelos interessados no sítio do Tribunal de Justiça do Estado do Rio de Janeiro.

\title{
3.2 Adaptação do procedimento - Caso 1
}

O primeiro caso trata de uma ação reparatória por danos imateriais proposta por JMOL face do Consórcio W. A autora aderiu à um consórcio de um carro e na ocasião foi ajustado o modelo do veículo, o período do consórcio e o valor da prestação. Após alguns meses, o Consórcio modificou o modelo do carro objeto do consórcio, o que acarretou aumento no valor das parcelas. Diante deste fato, a autora não mais permaneceu no consórcio e ajuizou ação para obter a devolução dos valores pagos, antes do fim consórcio, considerando que sua saída se deu em razão da prática abusiva e arbitrária da parte ré.

A ação foi ajuizada em 22/04/2020 e distribuída para 02a Vara Cível Regional de Madureira, sob o no 0007495-71.2020.8.19.0202. A referida ação tramitou pelo procedimento comum. O primeiro ato decisório proferido no processo, em 13/07/2020, teve o seguinte teor:

\begin{abstract}
Considerando-se: (a) o princípio processual de que não há nulidade sem prejuízo; (b) a possibilidade de que as partes alcancem a conciliação em qualquer momento do processo (artigos $3^{\circ}, \S 3^{\circ}$, parte final e $139, \mathrm{~V}$, do CPC/2015); (c) o direito fundamental constitucional à duração razoável do processo e dos meios que garantam a celeridade de sua tramitação (artigo $5^{\circ}$, LXXVIII, da CRFB/1988 e artigo $4^{\circ}$, do CPC/2015) reservo para momento oportuno a análise da necessidade e conveniência de designação de audiência de conciliação/mediação. Cite-se a parte ré para contestar o feito no prazo de 15 (quinze) dias úteis, sendo certo que, após a apresentação de resposta ou decurso do prazo para tanto, o feito deverá seguir o procedimento comum, tal como previsto no $\mathrm{CPC} / 2015$.
\end{abstract}

A primeira adaptação do procedimento, realizada sem menção ao art. 139, VI, do CPC, foi o afastamento da audiência de mediação/conciliação prevista no art. 334 do CPC, sob o fundamento de que não há nulidade sem prejuízo, destacando que a conciliação poderia ser realizada em outro momento processual e, por fim, o direito fundamental à duração razoável do processo. Não houve, nesta primeira adaptação do procedimento, o diálogo com as partes acerca do afastamento, ainda que temporário, da audiência de conciliação.

limitação da pesquisa realizada no sítio dos tribunais, pois podem ter ocorrido adaptações procedimentais que não foram objetos de recursos e, portanto, não aparecerão nas buscas. Por essa razão a pesquisa qualitativa, mais especificamente estudo de caso, pode nos possibilitar maior acesso à realidade da prática forense. 
Após o comparecimento espontâneo da parte ré para apresentar sua defesa, houve o segundo ato decisório proferido nos autos do processo, em 14/07/2020, onde o juiz determina o seguinte:

I. Tendo em vista o comparecimento espontâneo do réu aos autos, mediante a
apresentação de contestação, dou a mesma por citada, com arrimo no que
dispõe o artigo $239, \S 1^{\circ}$, do CPC. II. Em réplica, em cinco dias. III. Digam as
partes, em cinco dias, JUSTIFICADAMENTE, as provas que pretendem
produzir e o respectivo ponto controvertido a ser dirimido, devendo apresentar
no referido prazo e desde que seja formulado o respectivo requerimento, rol de
testemunhas (arts. $357, \S 4^{\circ}$ e 450 , ambos do CPC), quesitos (art. 465 CPC) e
prova documental suplementar (art. 435 CPC), sob pena de indeferimento.

Neste segundo ato decisório do processo, proferido um dia após o ato decisório anterior, o juiz determinou que a parte autora se manifestasse em réplica no prazo de 05 dias. Trata-se, portanto, de nova adaptação do procedimento, pois os artigos 350 e 351 determinam que a parte autora se manifeste em réplica, sobre fatos novos e questões processuais, em 15 dias. Após a apresentação da réplica pela parte autora a demanda foi julgada, no dia 15/08/2020, rejeitando os pedidos da autora. A ação foi distribuída em 22/04/2020 e julgada em 15/08/2020, aproximadamente 04 meses de tramitação.

Percebe-se que o órgão julgador optou, no primeiro ato decisório, em privilegiar o direito fundamental à efetiva duração razoável do processo. A partir deste valor constitucional, foi adaptado o procedimento de modo a atingir este fim, sem que fosse observado o contraditório-influência (art. 10 do CPC) e reduzindo prazo para manifestação em réplica para 05 dias. $\mathrm{O}$ art. 139, VI, do CPC é claro ao dispor sobre dilatação de prazo, inclusive peremptórios, mas não em redução.

O caso retrata uma aplicação da visão instrumentalista do processo em que o juiz definiu o objeto da atividade estatal, que seria desenvolvida por meio de adaptações do procedimento, almejando a solução da lide em tempo razoável (04 meses), mas sem observa a cooperação processual e o contraditório influência.

\subsection{Adaptação do procedimento - Caso 2}

O segundo caso trata de uma ação indenizatória proposta por DPD em face de TCSA pleiteando indenização por danos materiais e imateriais em razão dos defeitos na prestação de serviços de pacote de dados e de telefonia móvel. A ação foi distribuída em 19/11/2019, para a 06 $6^{\text {a }}$ Vara Cível do Fórum Regional do Méier, sob o nº 0030962-95.2019.8.19.0208, em período anterior ao início da pandemia, e a audiência de conciliação foi designada para o dia 23/03/2020.

No dia 16/03/2020 a audiência foi suspensa em razão do Ato Normativo Conjunto nº4 do Tribunal de Justiça do Estado do Rio de Janeiro, que suspendeu as atividades presenciais em razão da pandemia. 
Diante do tempo de paralisação das atividades presenciais, em 25/08/2020 foi publicado o seguinte despacho:

Considerando o tempo transcorrido pela paralisação das atividades forenses presenciais, intimem-se as partes para que informem, no prazo de 15 dias, se há possibilidade de acordo, e em caso positivo, que apresentem suas propostas. Vindas as propostas de acordo, intimem-se a partes para manifestação. As partes assistidas pela DP deverão ser intimadas por OJA.

Mesmo em regime jurídico extraordinário o juiz, diante da necessidade de adaptar o procedimento em razão da crise pandêmica, intimou às partes para que se manifestam acerca da possibilidade de resolução consensual do conflito. A parte autora se manifestou acerca da possibilidade de resolução consensual do conflito e a parte é, embora citada, permaneceu inerte. Diante da inércia da ré, o juiz proferiu, no dia 01/12/2020, o seguinte despacho:

Renove-se a citação da ré via portal eletrônico, uma vez que o termo inicial para oferecimento da contestação começa a fluir a partir da audiência de conciliação, nos termos do art. 335, I do CPC, que fica dispensada neste momento.

Neste caso, especificamente, o órgão julgador suspendeu a realização da audiência no dia 16/03/2020 em razão da pandemia. No entanto, no dia 25/08/2020 retomou a marcha processual, adaptando o procedimento em razão da crise sanitária observando, contudo, o contraditório-influência e condução dialógica do procedimento. Independente do desfecho deste caso, que na data da redação deste trabalho ${ }^{9}$ se encontra na fase postulatória, a condução do órgão julgador, no encaminhamento do procedimento, foi mais dialógica do que no primeiro caso.

\subsection{Adaptação do procedimento - Caso 3}

O terceiro caso diz respeito à uma demanda proposta por ASR em face de UVA cujo objeto se relaciona coma cobrança de mensalidades referentes a determinado curso universitário sem que a parte autora tenha sequer se matriculado na respectiva instituição de ensino. A ação foi distribuída em 16/12/2019 para a 04 ${ }^{a}$ Vara Cível Regional do Méier, sob o nº 003458218.2019.8.19.0208.

A demanda foi, portanto, distribuída em período anterior à crise pandêmica, mas seguiu tramitação diversa do segundo caso analisado. No dia 21/01/2020 o juiz determinou a citação da parte ré. A contestação foi juntada pela parte ré e em 17/09/2020 o Cartório certificou que a contestação e a réplica foram juntadas tempestivamente. No dia 24/11/2020 o juiz despachou determinando que as partes apresentem as provas que pretendem produzir, justificadamente ${ }^{10}$.

\footnotetext{
${ }^{9} \mathrm{O}$ texto foi redigido em $19 / 12 / 2020$.

${ }^{10}$ Este foi o último despacho proferido no processo até a redação deste trabalho.
} 
Verifica-se que em nenhum momento foi designada a audiência de conciliação e também não se verificou despacho no sentido de ouvir as partes acerca da possibilidade da resolução consensual da lide. $O$ órgão julgador encaminhou o procedimento sem sequer mencionar a suspensão da audiência de conciliação. Não se trata de mera formalidade, mas do afastamento de uma etapa obrigatória do procedimento sem observar o contraditório-influência e sem estabelecer um modelo cooperativo de diálogo entre os sujeitos processuais.

\section{CRISE PANDÊMICA E SEUS IMPACTOS NA CULTURA JURÍDICA PROCESSUAL}

A literatura especializada vem se debruçando sobre as modalidades de flexibilização do procedimento, observando as diversas perspectivas cerca do paradigma epistemológico de processo adotado. Os trabalhos de Luiz Rodrigues Wambier (2017), Fernando Gajardoni (2020), Igor Raatz e Willian Dietrich (2018), entre outros, são evidências neste sentido.

Entretanto, a análise dos casos apresentados acima aponta para alguns aspectos que precisam ser considerados no debate acadêmico e pragmático acerca da temática. Num período de crise pandêmica, em que se espera uma certa homogeneidade no encaminhamento das questões deduzidas em juízo, verifica-se uma dispersão qualitativa na condução da adaptação do procedimento comum.

É evidente que o artigo 139, VI, do Código de Processo Civil, trata de adaptação do procedimento considerando as peculiaridades do caso concreto. Não há dúvidas acerca disso. Porém, a adaptação do procedimento pelo juiz constitui modificação substancial em nossa cultura jurídica, o que demanda análise empírica acerca da aplicação do instituto de modo a identificar, na prática forense, quais são as variáveis que atuam nesta dinâmica e, principalmente, quais são as premissas utilizadas pelo órgão julgador para aplicar a adaptação procedimental.

A crise pandêmica nos possibilitou dimensionar, num regime jurídico extraordinário, como os órgãos do Poder Judiciário adequam o procedimento para dar conta dos desafios propostos em situação de anormalidade. Este período nos permitiu aferir, em alguma medida, como cada órgão julgador estabelece premissas e critérios para adequar o procedimento comum às especificidades da causa. A análise dos casos acima nos permitiu identificar pelo menos 03 tipos ideais de prática de órgãos julgadores, para usar as categorias weberianas, na adaptação do procedimento.

O primeiro tipo ideal, identificado no caso 01, concerne a uma prática judiciária em que o órgão julgador adequa o procedimento para efetivar valores e princípios por ele definido sem ouvir às partes acerca do processo decisório definido. Neste tipo-ideal o órgão jurisdicional se apresenta como uma instância que sabe, a priori, quais as adaptações necessárias num 
determinado caso concreto, independente da percepção das partes e terceiros acerca do conflito posto em juízo.

O segundo tipo-ideal, ilustrado pelo caso 02, é representado por um órgão julgador que, em alguma medida, observa o diálogo com os demais sujeitos processuais. Ainda que se assegure o contraditório, em sua configuração mais limitada, este tipo-ideal possibilita a construção participativa do processo decisório, em algum grau.

O caso 03 representa o terceiro tipo-ideal. O órgão julgador do caso 03 conduziu o procedimento sem considerar o regime jurídico extraordinário da pandemia. Embora a demanda tenha sido proposta em período anterior à crise, em nenhum momento foi mencionado a designado data para realização do referido ato, ou mesmo sua suspensão em razão da pandemia. Não foi oportunizado às partes, em nenhum momento, se manifestar acerca da possibilidade, ou não, da resolução consensual do conflito de interesses. O procedimento foi conduzido com alto grau de rotinização, o que evidencia que sequer houve uma análise das etapas processuais dos casos em tramitação no juízo.

Estes dados revelam um traço significativo da nossa cultura jurídica processual. $\mathrm{O}$ instrumentalismo processual informa fortemente nossas práticas judiciárias. A visão de que o processo é instrumento da jurisdição e a preponderância do papel do juiz na definição do melhor caminho a seguir são evidências que saltam aos olhos nos casos analisados. Se num regime extraordinário, em que se exige maior atenção e cautela dos órgãos jurisdicionais, o instrumentalismo processual se manifesta de forma contundente, o mesmo ocorrerá em diversas situações jurídicas que ocorrem diariamente nos diversos tribunais do país.

Os casos analisados tratam de relações de consumo. Entretanto, não se pode afirmar que em outras áreas do direito o encaminhamento seria diferente. $\mathrm{O}$ instrumentalismo processual conforma a nossa prática judiciária. Esta conformação decorre da prevalência, em alguma medida, de um senso comum dos juristas no sentido de que o instrumentalismo, ou mesmo outras leituras publicistas do processo, no campo do direito processual civil. Analisar a adaptação do procedimento pela epistemologia democrática, cooperativa ou mesmo garantista do processo permite, a um só tempo, maior controle da atividade do poder jurisdicional, como também maior democratização do processo decisório.

O principal impacto da crise no direito processual civil, principalmente no que tange a adaptação do procedimento, foi denunciar a visão publicista que ainda informa nossa cultura jurídica processual, principalmente a vertente do instrumentalismo processual. Esta tensão legitima a urgência do debate e a necessidade de se implementar um modelo de processo que assegura a plena efetividade das garantias constitucionais, de forma democrática, cooperativa e garantista. 


\section{CONCLUSÃO}

A adaptação ou flexibilização procedimental se constitui como técnica processual fundamental para dar maior efetividade do processo, ajustando-se às peculiaridades da causa. Embora não haja em nossa processualística vivência institucional suficiente acerca da aplicação da adaptação procedimental, o período de crise foi fundamental no sentido de se verificar a aplicação do instituto em processos judiciais que exijam adequação às exigências da causa. Entretanto, é imperioso que esta técnica seja aplicada observando o modelo cooperativo e democrático de processo ajustando-se às normas fundamentais do direito processual civil brasileiro.

A adaptação procedimental não deve ser realizada exclusivamente para viabilizar a efetiva administração da justiça. Deve ser aplicada, com efeito, para se obter o acesso a ordem jurídica justa, concretizando o direito posto em juízo em tempo razoável. Este objetivo somente será alcançado através da mudança epistemológica do processo.

\section{REFERÊNCIAS}

BARBOSA MOREIRA, José Carlos O neoprivatismo no processo civil, In: Temas de direito processual, Nona Série. São Paulo: Saraiva, 2007.

CABRAL, Trícia Navarro Xavier. Flexibilização procedimental. Revista de Direito Processual da UERJ, Rio de Janeiro. v. 6, n.6, 2010. Disponível em:https://www.epublicacoes.uerj.br/index.php/redp/article/view/21570. Acesso em: 26 set. 2020.

CATHARINA, Alexandre de Castro. Movimentos sociais e a construção dos precedentes judiciais. Curitiba: Juruá, 2015.

DINAMARCO, Candido Rangel. A instrumentalidade do processo. São Paulo: Malheiros Editores, 2002.

FILHO, Antônio Carvalho. Desmistificando o processo justo: pela reconstrução do devido processo legal. Empório do Direito, 2019. Disponível em:

https://emporiododireito.com.br/leitura/25-desmistificando-o-processo-justo-pelareconstrucao-do-devido-processo-legal. Acesso em: 19 dez. 2020.

GAJARDONI, Fernando da Fonseca. Flexibilização e combinação de procedimentos no sistema processual civil brasileira. Revista Eletrônica de Direito Processual da UERJ, Rio de Janeiro, RJ, v. 21, n. 3, p. 135-163, set. 2020. ISSN 1982-7636. Disponível em: https://www.e-publicacoes.uerj.br/index.php/redp/article/view/54201/34875. Acesso em: 26 set. 2020.

GRECO, Leonardo. Atos de disposição processual. Revista Eletrônica de Direito Processual da UERJ, Rio de Janeiro, RJ, v. 1, n. 1, p. 7-28, out. 2007. ISSN 1982-7636. 
Disponível em: https://www.e-publicacoes.uerj.br/index.php/redp/article/view/23657/16714. Acesso em: 26 set. 2020.

MARINONI, Luiz Guilherme; ARENHART, Sérgio Cruz; MITIDIERO, Daniel. Curso de Processo Civil: Tutela dos direitos mediante procedimento comum. v. 2. São Paulo: Revista dos Tribunais, 2015.

NUNES, Dierle José Coelho. Processo jurisdicional democrático: uma análise crítica das reformas processuais. Curitiba: Juruá, 2012.

RAATZ, Igor; ACHIETA, Natascha; DIETRICH, William. Processualismo científico e "fases metodológicas" do processo: a tática erística do adjetivo científico e das "novas fases metodológicas". Revista de Direito Processual da UERJ, Rio de Janeiro. v. 21, n.3, 2020. Disponível em: https://www.e-publicacoes.uerj.br/index.php/redp/article/view/54206. Acesso em: 26 set. 2020.

RAATZ, Igor; DIETRICH, William Galle. Técnica processual e (de) limitação dos poderes do juiz: contributos de uma leitura hermenêutica do processo civil. Revista de Direito Processual da UERJ, Rio de Janeiro. v. 19, n. 1., 2018. Disponível em: https://www.epublicacoes.uerj.br/index.php/redp/article/view/30717/23723. Acesso em: 19 dez. 2020.

WAMBIER, Luiz Rodrigues. O MODELO PROCESSUAL COOPERATIVO E A FLEXBILIZAÇÃO PROCEDIMENTAL. Revista Eletrônica de Direito Processual da UERJ, Rio de Janeiro, RJ, v. 18, n. 3, p. 238-255, set. 2017. ISSN 1982-7636. Disponível em: < https://www.e-publicacoes.uerj.br/index.php/redp/article/view/31696>. Acesso em: 10 maio 2020. 